\title{
PEPSIN AND THERMOLYSIN AS CATALYSTS OF PEPTIDE BOND SYNTHESIS
}

by

\author{
JOSEPH S. FRUTON
}

\author{
Kline Biology Tower, Yale University, New Haven, \\ Connecticut 06520 U.S.A.
}

Keywords: Aspartyl proteinases, metalloproteinases, enzyme specificity, Gibbs energy, kinetic parameters, transition state

\begin{abstract}
The early studies on proteinase-catalyzed peptide bond synthesis are summarized as background for a report on some recent work in our laboratory on pepsin and thermolysin. The primary and secondary specificity of these two enzymes have been found to be suitable for the preparative synthesis of oligopeptides by the condensation of two hydrophobic L-amino acid residues. Kinetic data are presented showing that the rate of entry of each of the two components in a thermolysin-catalyzed condensation reaction depends on the nature of the other component, and that this effect is related to differences in the transition-state conformation of the enzyme-reactant complexes.
\end{abstract}

\section{INTRODUCTION}

HEINZ HOLTER and I first met a half-century ago, and our affinity of thought about scientific problems and other matters cemented a lasting friendship. It is a source of joy, therefore, to participate in this collective tribute to him on the occasion of his eightieth birthday.

The subject of this paper has a long history, dating back at least to the beginning of this century (45). My involvement in it began in 1936, when HEINZ FrAENKEL-CONRAT and I were working together on the proteinase papain in the laboratory of MAX BERGMANN at the Rockefeller Institute for Medical Research (7). BERGMANN asked us to study the action of phenylhydrazine on this enzyme because he thought that there might be an aldehyde group in its active site. Shortly before, LEONIDAS
ZERVAS and I had found a series of simple synthetic substrates for papain, among them Z-Gly-NH $\mathrm{NH}_{2}(8)$, and when FRAENKEL-CONRAT incubated this compound with phenylhydrazine (or aniline) in the presence of papain, there gradually appeared a crystalline precipitate soon identified as Z-Gly-NHNHPh (or Z-Gly-NHPh) (4). In a control experiment, he replaced Z-Gly$\mathrm{NH}_{2}$ by Z-Gly-OH; the same product was obtained, demonstrating for the first time the unequivocal synthesis of an amide bond in a condensation catalyzed by a proteinase. However, the rate of product formation was more rapid with Z-Gly- $\mathrm{NH}_{2}$, and we concluded that with this substrate there was a direct replacement of the amide- $\mathrm{NH}_{2}$ group by phenylhydrazine (or aniline), rather than prior hydrolysis to Z-Gly-OH. This was the first case

\footnotetext{
Abbreviations: $\mathrm{Bz}=$ benzoyl; $\mathrm{Bzl}=$ benzyl; DMSO = dimethylsulfoxide; FA = furylacryloyl; HPLC $=$ high performance liquid chromatography; $\mathrm{OMe}=$ methoxy; $\mathrm{Ph}=$ phenyl; Tris = tris-(hydroxymethyl)amino methane; $\mathrm{Z}=$ benzyloxycarbonyl. The abbreviated designation of amino acid residues denotes the $\mathrm{L}$ form, unless otherwise stated.
} 
of a well-defined proteinase-catalyzed transamidation, a term used extensively in my later studies on such acyl-transfer reactions $(17,30)$.

In parallel with the studies on papain, I had also found the first synthetic peptide substrates for chymotrypsin (5), which had just been crystallized by KUNITZ (33). Among them was Bz-Tyr-Gly- $\mathrm{NH}_{2}$, which was cleaved specifically at the Tyr-Gly bond. FraENKEL-CONRAT'S discovery led me to incubate Bz-Tyr-OH with $\mathrm{H}-\mathrm{Gly}-\mathrm{NHPh}$ in the presence of chymotrypsin. Bz-Tyr-Gly-NHPh crystallized from the reaction mixture, and with $\mathrm{Bz}-\mathrm{Tyr}-\mathrm{NH}_{2}$ as the acyl donor the product was formed more rapidly (6). We did not continue these studies on the synthetic action of papain and chymotrypsin because FRAENKEL-CONRAT left BERGMANN'S laboratory soon afterward, and I had shifted to a search for peptide substrates for pepsin. Then came the Second World War, when we were obliged to work on other problems, and in 1945 I moved to Yale University.

Thanks to the generosity of WARREN WEAVER of the Rockefeller Foundation, I had the opportunity in 1948 of making extended visits to several important European laboratories, in particular the Carlsberg. The rigors of the Nazi occupation were still remembered, but the spirit of the laboratory was exhilarating, because of the genius of KAJ LINDERSTRøMLANG, the warmth and insight of HEINZ HOLTER, and the enthusiasm of younger members, notably MARTIN OTTESEN. As for so many visitors from abroad to the Carlsberg Laboratory, acquaintance soon ripened into friendship, for me leavened by discussions with LINDERSTRøM-LANG about the thermodynamics of peptide bond synthesis. The views he held at that time on this subject were presented shortly afterward in his Lane Lectures (35).

This encounter led me to make the first direct measurement of the equilibrium constant in the proteinase-catalyzed condensation of two amino acid residues to form a peptide bond. Bz-Tyr-OH was incubated at pH 7.9 for extended periods with ${ }^{15} \mathrm{~N}$-labeled $\mathrm{H}-\mathrm{Gly}-\mathrm{NH}_{2}$ in the presence of chymotrypsin, carrier unlabeled Bz-Tyr-Gly- $\mathrm{NH}_{2}$ was added, and the dipeptide derivative was recrystallized to constant isotope content. The amount of synthesis was small
(0.32 mmoles from 25 mmoles Bz-Tyr-OH and 50 mmoles $\mathrm{H}-\mathrm{Gly}-\mathrm{NH}_{2}$ ), but sufficient to permit the calculation of an equilibrium constant $\left(\mathrm{K}_{\mathrm{syn}}\right)$ of $0.49 \mathrm{M}^{-1}$ for the process:

$$
\begin{aligned}
& \mathrm{RCOO}^{-}(1 \mathrm{M})+{ }^{+} \mathrm{NH}_{3} \mathrm{R}^{\prime}(1 \mathrm{M})= \\
& \operatorname{RCONHR}(1 \mathrm{M})+\mathrm{H}_{2} \mathrm{O}(\text { liq })
\end{aligned}
$$

This value corresponds to an apparent Gibbs energy change of $0.4 \mathrm{kcal}$ per mole. My colleague JULIan StURTEVANT and his student ALAN DOBRY performed calorimetric measurements on the same system, and their value for the enthalpy change ( $1.55 \mathrm{kcal}$ per mole) allowed us to estimate the entropy change $(3.8 \mathrm{cal}$ per mole per deg) under the conditions of the experiment (12).

It was clear from the start that in the chymotrypsin-catalyzed synthesis of Bz-Tyr-Gly- $\mathrm{NH}_{2}$ from Bz-Tyr-OH and $\mathrm{H}-\mathrm{Gly}-\mathrm{NH}_{2}$ the yield of synthetic product is approximately proportional to the initial concentrations of the two reactants. Thus, to raise the yield from the 1.3 per cent found under the conditions noted above, for 25 mmoles of Bz-Tyr-OH one would need approximately 2 moles of $\mathrm{H}$-Gly- $\mathrm{NH}_{2}$ to attain 50 per cent synthesis. When $\mathrm{H}-\mathrm{Gly}-\mathrm{NH}_{2}$ is replaced by the more hydrophobic H-Gly$\mathrm{NHPh}$, the yield is nearly quantitative because the solubility of the synthetic product is less than the equilibrium concentration, and the endergonic condensation reaction is coupled to the exergonic removal of the product from the aqueous solution.

Aside from showing that the thermodynamic values used at that time in relation to the problem of protein biosynthesis were incorrect, the paper of DOBRY et al. (12) called attention to the importance of the ionization constants of the carboxyl $\left(K_{A}^{\prime}\right)$ and amino $\left(K_{B}^{\prime}\right)$ groups that participate in the condensation reaction. We described this relationship by means of an equation for the hydrolytic process:

$$
\begin{aligned}
\mathrm{K}_{\mathrm{app}}^{\prime}= & \left([\mathrm{RCOOH}]\left[\mathrm{NH}_{2} \mathrm{R}^{\prime}\right]\right) /\left[\mathrm{RCONHR}^{\prime}\right]= \\
& \left(1+\left(\mathrm{a}_{\mathrm{H}} / \mathrm{K}_{\mathrm{A}}^{\prime}\right)+\left(\mathrm{K}_{\mathrm{B}}^{\prime} / \mathrm{a}_{\mathrm{H}}\right)\right) \mathrm{K}_{\text {hyd }}^{\prime}
\end{aligned}
$$

where the quantities in brackets are total concentrations including both charged and uncharged forms. CARPENTER (11) later developed this theme more fully, and noted that the observed unfavorable equilibria for peptide bond synthesis in aqueous solution are largely a consequence of the thermodynamic work needed 
to convert carboxylate and ammonium groups to their uncharged forms. According to his "non-ionized compound convention" the condensation of $\mathrm{RCOOH}$ and $\mathrm{NH}_{2} \mathrm{R}$ ' is strongly exergonic.

This is where the matter rested in 1960 , and scant attention was paid to it until the appearance in 1978 of the important paper by HOMANDBERG et al. (22) from the laboratory of MICHAEL LASKOWSKI, Jr. They determined the equilibrium constant in the chymotrypsincatalyzed condensation of Z-Trp-OH and $\mathrm{H}$ Gly- $\mathrm{NH}_{2}$ by means of HPLC separation and spectrophotometric analysis of the reaction components, and found a value of $\mathrm{K}_{\text {syn }}^{,}$of 0.45 $\mathbf{M}^{-1}$ at $\mathrm{pH} 7.9$, in good agreement with that reported by DOBRY et al. (12). Moreover, HOMANDBERG et al. showed that the addition of an organic co-solvent (e.g., glycerol, dimethyl sulfoxide, 1,4-butanediol) causes a marked increase in $K_{\text {syn }}^{\prime}$ as a consequence of a shift in the $\mathrm{pK}_{\mathrm{A}}^{\prime}$ of Z-Trp-OH. A careful study of the $\mathrm{pH}$ dependence of $\mathrm{K}_{\text {syn }}$ gave data in excellent accord with the equation given above.

LASKOWSKI'S paper led to a revival of interest in the possibility of using specific proteinases for the preparative synthesis of peptides. Although the potential of this method had been recognized earlier (16), it did not appear to be needed because the art of chemical peptide synthesis had developed rapidly, in response to the recognition that many hormones and antibiotics are peptides. Valuable new coupling methods and protecting groups had been added to the armamentarium of the synthetic peptide chemist, and many successes had been achieved in the laboratory synthesis of biologically-active peptides., Difficulties still abound, however, especially in the synthesis of long-chain peptides, whether by solution or solid-phase methods. For this reason, peptide chemists have recently begun to develop procedures involving proteinase-catalyzed reactions; an early example is the use of trypsin to convert swine insulin to human insulin (24). Other proteinases (chymotrypsin, papain) with a broader primary specificity than that of trypsin have been used to good advantage in the synthesis of shorter peptides $(20,26)$. The stereospecificity with respect to the preferred amino acid residue is a partic- ularly valuable feature of such proteinase-catalyzed condensation reactions, since chemical coupling methods often cause considerable racemization. Also, enzyme-catalyzed synthesis may be advantageous because the precipitation of an insoluble product frequently gives material of higher purity and in higher yield. There are disadvantages, however, notably the occurrence of unwanted hydrolytic or transamidation reactions.

In addition to the reversal of hydrolytic reactions, the serine and cysteine proteinases catalyze peptide bond formation by the aminolysis of acylamino acid esters (e.g., Bz-Tyr-OEt) in a strongly exergonic process (10). In such reactions, the intermediate formation of an acyl-enzyme is well established; the same mechanism is assumed for the conversion of acylamino acid amides to peptides in transamidation reactions (15), with the difference that the rate-limiting step is the formation of the acyl-enzyme, whereas with ester substrates it is the deacylation of the acyl-enzyme (3). In the action of the cysteine proteinases, the intermediate acyl-enzyme is a thiol ester, which reacts more rapidly with amines than does an analogous hydroxy ester; enzymes such as papain or cathepsin B are therefore much more effective catalysts of transamidation reactions than are chymotrypsin or trypsin (14). It is also noteworthy that the ratio of the rates of hydrolysis of an ester substrate to that for an analogous amide substrate is much lower (5-100) with the cysteine proteinases than with the serine proteinases $\left(10^{4}-10^{5}\right)$.

In recent years, there have been numerous reports on the synthesis of small oligopeptides with chymotrypsin or trypsin as the catalyst in the aminolysis of ester substrates. With suitable choice of blocked reaction components, solvents, $\mathrm{pH}$, and enzyme concentration, the desired peptide derivatives were obtained in good yield $(20,26)$. It should be noted that the primary specificity for the so-called $P_{1}$ residue is qualitatively the same as in hydrolysis, and is much broader in the aminolysis of ester substrates than in condensation reactions. For example, trypsin hydrolyzes acylglycine esters slowly, and catalyzes their aminolysis by amino acid amides (e.g., H-Leu- $\mathrm{NH}_{2}$ ), but the trypsincatalyzed coupling of an acidic component such 
as Bz-Tyr-Gly-OH with $\mathrm{H}-\mathrm{Leu}-\mathrm{NH}_{2}$ would not be feasible. If one assumes the obligatory formation of an acyl-enzyme in the condensation reaction, one can readily understand why the reversal of hydrolysis by serine proteinases usually requires a much higher enzyme concentration (approximately tenfold) and much longer time (hours instead of minutes) than in aminolysis reactions; these differences may be considered to reflect the relative concentrations of the acyl-enzyme in the stationary state of enzyme catalysis. Advantage has also been taken of the fact that it is possible to perform aminolyses at $\mathrm{pH}$ values near 10 ; since the $\mathrm{pK}_{\mathrm{B}}^{\prime}$ of carboxyl-blocked amino acids is approximately 7.5 , and only the unprotonated amine can act as a nucleophile, the acyl-transfer reaction is more effective at the higher $\mathrm{pH}$ value. Moreover, as shown in the important studies of JOHANSEN on peptide synthesis by means of the serine. enzyme carboxypeptidase $\mathrm{Y}(52)$, the hydrolysis of peptide bonds is much less at $\mathrm{pH} 10$ than at $\mathrm{pH} 7.5$, although unwanted transamidation reactions (e.g., polymerization of amino acid amides) are also favored at the higher $\mathrm{pH}$ value.

At the present state of knowledge, it appears unlikely that the proteinase-catalyzed synthesis of oligopeptides will supplant the well-established coupling methods, but one may expect that peptide chemists will use the enzymatic method more frequently than before, in particular for syntheses in which racemization is a serious problem. For this purpose, more information is needed about the secondary specificity of well-known proteinases; also, systematic studies on other enzymes may open new possibilities for practical application. Moreover, as will be suggested in what follows, the study of the kinetics of enzymatic peptide synthesis may contribute to a better understanding of the mechanism of enzymes that act at peptide bonds. During the past two years, this has been a major objective of our work on peptide bond synthesis by pepsin and thermolysin.

\section{PEPSIN-CATALYZED PEPTIDE BOND SYNTHESIS}

The available data on the structure and action of the so-called aspartyl proteinases (gastric pepsin, penicillopepsin, Rhizopus pepsin, etc.), with $\mathrm{pH}$ optima in the range $2-5$, are consistent with a general acid-base catalytic mechanism for the hydrolytic cleavage of a peptide bond (27). According to this mechanism, an aspartyl carboxylate group (Asp-32 of pepsin) acts as a general base in the attack of a water molecule at the carbonyl-carbon and an aspartyl carboxyl group (Asp-215) acts as a Lewis acid at the carbonyl-oxygen. The mechanism does not predict the intermediate formation of a covalent acyl-enzyme (an acid anhydride) nor a covalent imino-enzyme of the kind postulated earlier (40), but rather the non-covalent interaction with the active site of a transition-state species akin to a tetrahedral intermediate. Efforts to detect spectroscopically a covalent enzyme-substrate intermediate have failed thus far (13), and, in contrast to the results with serine proteinases, ${ }^{18} 0$ isotope-exchange experiments (2) have given data inconsistent with the formation of such an intermediate.

The apparent difference in the general mechanism of the aspartyl proteinases, as compared with that of the serine and cysteine proteinases, is clearly related to a difference in primary specificity. Whereas a serine proteinase such as chymotrypsin hydrolyzes not only ZTyr-Gly-NH $\mathrm{NH}_{2}$ at the Tyr-Gly bond, but also a host of Z-Tyr derivatives including Z-Tyr-OMe and $\mathrm{Z}-\mathrm{Tyr}-\mathrm{NH}_{2}$, pepsin requires the presence, in small oligopeptide substrates, of a hydrophobic L-amino acid residue as the donor of the $\mathrm{NH}$ group of the sensitive bond. Pepsin also attacks ester linkages, but the oxygen of the sensitive bond cannot be provided by a methoxy group but must be donated by a hydrophobic L-hydroxy acid such as $\beta$-phenyl-L-lactic acid (23). Extensive studies on the primary specificity of pepsin have shown a preference for peptide bonds linking two aromatic L-amino acid residues, as in oligopeptide substrates of the type A-Phe-Phe-B. Modification of the A and B groups of such substrates by chain elongation or alteration of the component amino acid residues gave evidence for enzyme-substrate interactions at both sides of the sensitive PhePhe bond $(18,19)$. Of special interest was the finding that whereas there was considerable variation (1000-fold) in the value of $k_{\text {cat }}$ for the 
hydrolytic cleavage of the Phe-Phe bond, the value of $K_{m}$ changed to a smaller degree (10fold). Since the observed $K_{m}$ was shown to represent the dissociation constant of the ground-state Michaelis complex, the rate-limiting step in the catalytic process is the conversion of this complex to the transition-state enzymesubstrate complex, but more effective catalysis is not necessarily a consequence of tighter binding in the ground state, as has been inferred for chymotrypsin (32). We therefore proposed some years ago (19) that a portion of the Gibbs energy in the binding of an oligopeptide at the extended active site of pepsin is used to lower the energy of activation in the catalytic process. Thus, the effect of the secondary interactions at a distance from the locus of catalytic action is to cause tighter binding in the transition state. Such transition-state stabilization can be ascribed to various factors (29), in particular to conformational changes in the active site. The suggestion that the active site of pepsin is a flexible structure was based initially on kinetic data and on fluorescence studies on the binding of substrates labeled with extrinsic probe groups (44), and has recently received strong support from X-ray crystallographic studies on penicillopepsin (28).

The above considerations lead to the hypothesis that in the hydrolytic action of pepsin on an oligopeptide substrate, the order of release of products depends on the structure of both fragments and not on the intermediate formation of a covalent acyl- or imino-enzyme (19). According to this view, the interaction of the hydrolytic products with active-site groups may be coupled, so that the nature of one product may influence the rate of departure of the other through the effect it has on the conformational state of the active site. A corollary is that in the reverse direction the nature of one reactant on the condensation process may influence the rate of entry of the other reaction partner.

To test this inference, we selected initially the pepsin-catalyzed condensation of acidic components of the type Z-A-Phe-OH (where A was varied) and an excess of various amine components (H-Phe-NHPh, H-Phe-OBzl, H-Leu$\mathrm{NHPh}$, etc.). The choice of the reactants was based on the available knowledge of the hydro- lytic specificity of pepsin, and on preliminary experiments showing that at a suitable enzyme concentration such condensation reactions proceed to over 95 per cent synthesis of the expected product within $2 \mathrm{hr}$. Under the experimental conditions chosen (50 per cent ethylene glycol, apparent $\mathrm{pH} 4.5,37^{\circ} \mathrm{C}$ ), the solubility of the products is below the expected equilibrium concentration, and the rate of their precipitation is not rate-limiting in the over-all process. The reaction was stopped at various time intervals (5-100 $\mathrm{min}$ ) by the addition of a large volume of organic solvent to denature the enzyme and to dissolve the products in a system suitable for HPLC analysis. Longer incubation periods were avoided, since occasionally HPLC analysis gave evidence of the formation of transpeptidation products which accumulate with time. It should be noted, however, that the HPLC effluent diagrams used in our studies (9) for the estimation of the rates of condensation did not show the presence of measurable quantities of such products. TSENG et al. (48) have recently reported the occurrence of transpeptidation reactions upon the prolonged incubation of Z-Phe-OH and H-Phe-OBzl in the presence of high protein concentrations. As shown by SILVER and JAMES (47), the appearance of transpeptidation products in slow pepsin-catalyzed hydrolysis of poor oligopeptide substrates is a consequence of the occurrence of condensation reactions.

The rate data obtained in our studies accorded satisfactorily with first-order kinetics for the entry of Z-A-Phe-OH into the condensation reaction, and the effect of the variation of the A group and the amine component indicated that both the primary and secondary specificity of the hydrolytic action of pepsin is evident in the synthetic process (9). Subject to several assumptions, the $\mathrm{k}_{\mathrm{ca}} / \mathrm{K}_{\mathrm{m}}$ values for the entry of a variable acidic component into the condensation reaction were in the same ratio as that found earlier for the effect of analogous structural changes in soluble pepsin substrates (21). We were unable, however, to find satisfactory experimental conditions for the proposed study of the effect of variations in the nature of one component on the rate of entry of the other into the condensation reaction, because of the 
limited solubility of the Z-A-Phe-OH compounds in solvents that did not inactivate the enzyme.

The results obtained thus far in our laboratory, and by other investigators $(38,43)$, indicate that the aspartyl proteinases may be useful for coupling reactions in which it is desired to join two hydrophobic amino acid residues. An example is the pepsin-catalyzed condensation, recently performed by Dr. MICHAEL GELB in my laboratory, of Z-Tyr(Bzl)-Gly-Gly-Phe-OH with $\mathrm{H}$-Met-Arg $\left(\mathrm{NO}_{2}\right)$-Phe-OBzl to produce fully-protected pro-Met-enkephalin.

\section{THERMOLYSIN-CATALYZED PEPTIDE BOND SYNTHESIS}

Thermolysin is metalloproteinase whose optimal catalytic action near pH 7.5 involves the participation of a zinc ion (34) that serves as a Lewis acid in activating the carbonyl group of the sensitive bond of peptide and ester substrates in a manner analogous to the role of the Asp-215 carboxyl group of pepsin at acidic $\mathrm{pH}$ values. As in the proposed mechanism for pepsin, the carbonyl-carbon of the sensitive bond is considered to be attacked by a water molecule, with the carboxylate group of Glu-143 serving as a general base $(31,51)$. The hydrolytic specificity of thermolysin is directed to the preferential cleavage of peptide bonds in which the imino group is donated by a hydrophobic amino acid residue such as Phe or Leu $(36,37)$. Although the donor of the carbonyl bond of the sensitive bond may be Gly (a standard substrate is FA-Gly-Leu-NH $\mathrm{N}_{2}$ whose cleavage at the GlyLeu bond may be followed spectrophotometrically), replacement of the Gly residue by a Phe residue greatly enhances the rate of hydrolysis. In its general mechanism and its primary specificity, therefore, thermolysin resembles pepsin and related aspartyl proteinases. It differs markedly, however, from pepsin in its secondary specificity (36).

The ability of thermolysin to catalyze condensation reactions leading to the formation of blocked oligopeptides has been demonstrated in several recent studies $(25,41,50)$. Of special interest is the use of thermolysin to condense $\mathrm{Z}$-Asp-OH with $\mathrm{H}$-Phe-OMe, as a convenient route for the synthesis of aspartame (42). In our experiments $(21,50)$, the kinetics of thermolysin-catalyzed peptide bond synthesis were determined in the manner described above for pepsin, and the relative initial rates of formation of various di-, tri- and tetrapeptide derivatives were found to be similar to the relative rates of the hydrolytic cleavage of comparable soluble thermolysin substrates. Some striking effects of secondary specificity were found: for example, when the Gly residue of Z-Gly-Phe-OH is replaced by Ala, there is a large enhancement of the rate of condensation with a standard amino component such as H-Leu-NHPh. This effect is especially marked in the relative rates of synthesis with Z-Ala-Gly-OH or Z-Gly-Gly-OH as the acidic component; under the conditions of our experiments the ratio of the initial rates was approximately 300 . Information of this kind is likely to be useful in the choice of thermolysin for preparative peptide synthesis.

In view of the similarity of thermolysin and pepsin in mechanism and primary specificity, an attempt was made to find suitable conditions for kinetic experiments to determine whether variation in the nature of one component influences the rate of entry of the other component into a proteinase-catalyzed condensation. As was noted above, this proved to be unattainable with pepsin, largely because of the sparing solubility of Z-Phe-OH at $\mathrm{pH} 4.5$ and because the addition of organic cosolvents that increased its solubility sufficiently also led to enzyme inactivation. In the case of thermolysin, however, which acts at $\mathrm{pH} 7.5$, such experiments were possible. For example, the kinetics of the condensation of Z-Phe-OH were determined at single high concentrations of H-Phe-OMe or H-Phe-Gly-OMe. The initial rate data accorded satisfactorily with the Lineweaver-Burk form of the equation (46) for a rapid equilibrium random bireactant system that obeys MichaelisMenten kinetics:

$\frac{1}{v}=\frac{\alpha k_{m}(B)}{k_{\text {cat }}[E]_{0}}\left[1+\frac{k_{m}(A)}{[\bar{A}]}\right] \frac{1}{[B]}+\frac{1}{k_{c a t}[E]_{0}}\left[1+\frac{\alpha k_{m}(A)}{[A]}\right]$

The data for the kinetic parameters are given in Table $I$, where $\alpha$ is the interaction coefficient for the effect of one reactant on the binding of the other. 
TABLE I.

Approximate kinetic parameters for the entry of Z-Phe-OH (A) into thermolysin-catalyzed condensation reactions.

\begin{tabular}{lllll}
\hline Amine component $(B)$ & $\begin{array}{l}\mathrm{k}_{\text {cal }} \\
\mathrm{min}^{-1}\end{array}$ & $\begin{array}{l}\mathrm{K}_{\mathrm{m}}(\mathrm{A}) \\
\mathrm{mM}\end{array}$ & $\begin{array}{l}\mathrm{K}_{\mathrm{m}}(\mathrm{B}) \\
\mathrm{mM}\end{array}$ & $\alpha$ \\
\hline H-Phe-OMe & 125 & 20 & 300 & 0.125 \\
H-Phe-Gly-OMe & 12.500 & 65 & 500 & 0.125 \\
\hline
\end{tabular}

[Z-Phe-OH] $=5-25 \mathrm{mM}$ ( 5 concentrations for each concentration of amine component); [ $\left.\mathrm{NH}_{2} \mathrm{R}^{\prime}\right]=50-250 \mathrm{mM}$ ( 5 concentrations); enzyme concentration, $0.01 \mu \mathrm{M}$ for H-Phe-OMe, $0.0005 \mu \mathrm{M}$ for H-Phe-Gly-OMe; $10 \% \mathrm{DMSO}$; $0.5 \mathrm{M}$-Tris $0.05 \mathrm{M}-\mathrm{Ca}(\mathrm{Ac})_{2}$ buffer $\mathrm{pH} 7.5 ; 37^{\circ} \mathrm{C}$.

The data in Table I show that, for the two condensation reactions studied, the apparent $\mathrm{k}_{\text {cat }}$ and $\mathrm{K}_{\mathrm{m}}$ values for the entry of Z-Phe-OH depend on the nature of the amine component, with a much larger change in $\mathrm{k}_{\mathrm{rat}}$ than in $\mathrm{K}_{\mathrm{m}}$. A similar result was obtained with other amine components, for example $\mathrm{H}$-Leu- $\mathrm{NH}_{2}$ and H-Leu$\mathrm{NHPh}(50)$. These findings support the view that the conformation of the Z-Phe-OH binding site is influenced by the presence of the amine component in its own locus within the extended active site of thermolysin. It should be noted that other bireactant systems leading to ternary enzyme-substrate complexes have shown an analogous behavior. A notable example is the demonstration (49) that in the yeast hexokinasecatalyzed transfer of the terminal phosphate of ATP to glucose, the $\mathrm{K}_{\mathrm{m}}$ for Mg-ATP is about $60 \mu \mathrm{M}$, whereas for the reaction in which water is the phosphate acceptor the $\mathrm{K}_{\mathrm{m}}$ for $\mathrm{Mg}$-ATP is about 100 times greater. This result, together with X-ray diffraction data (1) showing a significant conformational change in yeast hexokinase upon the binding of glucose, suggest a large effect at the level of the ground-state Michaelis complex. In the case of thermolysin, the effect of changing the nature of the amine component on the apparent $\mathrm{K}_{\mathrm{m}}$ is relatively small as compared with the effect on $k_{\text {cat }}$, suggesting that the major influence of this change is exerted at the level of the transition-state complex. Moreover, as in the action of pepsin, the occurrence of transpeptidation reactions in the hydrolysis of poor substrates by thermolysin may indicate, not the formation of covalent acyl- or imino-enzyme intermediates (39), but the coupled interaction of the products with the active site and peptide synthesis in condensation reactions.

\section{ACKNOWLEDGEMENT}

The research of our laboratory reported in this paper was aided by grant GM-18172 from the National Institutes of Health.

\section{REFERENCES}

1. Anderson, C.M., E.H. Zucker \& T.A. SteitZ: Space-filling models of kinase clefts and conformational changes. Science 204, 375-380 (1979)

2. Antonov, V.K. L.M.GinOdMAN. Y.V.KaPITANNikov, T.N. BARShEVSKayA, A.G. Gurov \& L.D. RUMSH: Mechanism of pepsin catalysis. General base catalysis by the active site carboxylate ion. FEBS Letters 88, 87-90 (1978)

3. BENDER, M.L. \& F.J. KEZDY: Mechanism of action of proteolytic enzymes. Annu. Rev. Biochem. 34, 49-76 (1965)

4. Bergmann, M. \& H. Fraenkel-Conrat: The role of specificity in enzymatic synthesis of proteins. Syntheses with intracellular enzymes. J. Biol. Chem. 119, 707-720 (1937)

5. BergmanN, M. \& J.S. Fruton: On proteolytic enzymes. XIII. Synthetic substrates for chymotrypsin. J. Biol. Chem. 118, 405-415 (1937)

6. BergmanN. M. \& J.S. Fruton: Some synthetic and hydrolytic experiments with chymotrypsin. J. Biol. Chem. 124, 321-329 (1938)

7. Bergmann, M., J.S. Fruton \& H. FraenkelCONRAT: On proteolytic enzymes. XV. Regarding the general nature of intracellular proteolytic enzymes. J. Biol. Chem. 119, 35-46 (1937)

8. BergmanN. M., L. Zervas \& J.S. Fruton: On proteolytic enzymes. VI. On the specificity of papain. J. Biol. Chem. 111, 225-244 (1935)

9. Bozler, H. S.I. WAYNE \& J.S. Fruton: Specificity of pepsin-catalyzed peptide bond synthesis. Int. J. Peptide Protein Res. 20, 102-109 (1982)

10. Brenner, H., H.R. Muller \& R.W. Pfister: Eine neue enzymatische Peptidsynthese. Helv. Chim. Acta 33, 568-591 (1950) 
11. Carpenter, F.H.: The free energy change in hydrolytic reactions. The non-ionized compound convention. J.Am. Chem. Soc. 82, 1111-1122 (1960)

12. Dobry. A.. J.S. Fruton \& J.M. Sturtevant: Thermodynamics of hydrolysis of peptide bonds. J. Biol. Chem. 195, 149-154 (1952)

13. Dunn. B.M., T. Hofmann \& A.L. Fink: Cryoenzymological studies of the aspartyl proteinases, pig pepsin and penicillopepsin. Fed. Proc. 41, 762 (1982)

14. Durell. J. \& J.S. Fruton: Proteinase-catalyzed transamidation and its efficiency. J. Biol. Chem. 207, 487-500 (1954)

15. Fastrez, J. \& A.R. Fersht: Demonstration of the acyl-enzyme mechanism for the hydrolysis of peptides and anilides by chymotrypsin. Biochemistry 12, 2025-2034 (1973)

16. FRUTON, J.S.: The synthesis of peptides. Advances in Protein. Chemistry 5, 1-82 (1949)

17. FRUton, J.S.: Enzymic hydrolysis and synthesis of peptide bonds. Harvey Lectures 51, 64-87 (1957)

18. FRUTON, J.S.: The specificity and mechanism of pepsin action. Advances in Enzymology 33, 401443 (1970)

19. FRUTON. J.S.: The mechanism of the catalytic action of pepsin and related acid proteinases. Advances in Enzymology 44, 1-36 (1976)

20. Fruton, J.S.: Proteinase-catalyzed synthesis of peptide bonds. Advances in Enzymology 53, 239306 (1982)

21. Fruton, J.S.: Proteinases as catalysts of peptide synthesis. Trans. New York Acad. Sci. 41, 49-56 (1983)

22. Homandberg, G.A., J.A. Mattis \& M. LasKOWSKI, JR.: Synthesis of peptide bonds by proteinases. Addition of cosolvents shifts peptide bond equilibria towards synthesis. Biochemistry 17, 5220-5227 (1978)

23. INOUYE, K. \& J.S. Fruton: Studies on the specificity of pepsin. Biochemistry 6, 1765-1776 (1967)

24. InOUYe, K., K. Watanabe, K. Morihara, Y. TOChino, T. Kanaya, J. EMURa \& S. SaKakibara: Enzyme-assisted semisynthesis of human insulin. J. Am. Chem. Soc. 101, 751-752 (1979)

25. Isowa, Y. \& T. ICHIKawa: Syntheses of $\mathrm{N}$-acyl dipeptide derivatives by metalloproteinases. Bull. Soc. Chem. Jap. 52, 796-800 (1979)

26. JAKUBKE, H.D. \& P. KUHL: Proteasen als Biokatalysatoren für die Peptidsynthese. Die Pharmazie 37, 89-106 (1982)

27. JaMes, M.N.G., I.N. HSU \& L.T.J. Delbaere: Mechanism of acid protease catalysis based on the crystal structure of penicillopepsin. Nature 267,
808-813 (1977)

28. James, M.N.G., A. Sielecki, F. Salituro. D.H. RICH \& T. HOFMANN: Conformational flexibility in the active site of aspartyl proteinases revealed by a pepstatin fragment binding to penicillopepsin. Proc. Natl. Acad. Sci. USA 79, 6137-6141 (1982)

29. JENCKS, W.P.: Binding energy, specificity and enzymic catalysis - the Circe effect. Advances in Enzymology 43, 219-240 (1975)

30. JoHnSON, R.B., M.J. MyceK \& J.S. Fruton: Catalysis of transamidation reactions by proteolytic enzymes. J. Biol. Chem. 185, 629-641 (1950)

31. Kester, W.R. \& B.W. Matthews: Crystallographic study of the binding of dipeptide inhibitors to thermolysin: Implications for the mechanism of catalysis. Biochemistry 16, 2506-2516 (1977)

32. KNOWLES, J.R.: Enzyme specificity. a-Chymotrypsin. J. Theoret. Biol. 9, 213-228 (1965)

33. Kunitz, M. \& J.H Northrop: Crystalline chymo-trypsin and chymo-trypsinogen. I. Isolation, crystallization and general properties of a new proteolytic enzyme and its precursor. J. Gen. Physiol. 18, 433-458 (1935)

34. Latt, S.A., B. HolmQuist \& B.L. Vallee: Thermolysin: A zinc metalloenzyme. Biochem. Biophys. Res. Commun. 37, 333-339. (1969)

35. Linderstrøm-LANG, K.: Lane Medical Lectures. Proteins and Enzymes Stanford, California, pp. 93-115 (1952)

36. MORGAN, G. \& J.S. Fruton: Kinetics of the action of thermolysin on peptide substrates. Biochemistry 17, 3562-3568 (1978)

37. Morihara, K.: Comparative specificity of microbial proteinases. Advances in Enzymology 41, 179-243 (1974)

38. Morihara, K. \& T. OKa: Peptide bond synthesis catalyzed by subtilisin, papain and pepsin. J.Biochem. 89, 385-395 (1981)

39. Morihara, K., H. Tsuzuki \& T. Oka: Acyl and amino intermediates in reactions catalyzed by thermolysin. Biochem. Biophys. Res. Commun. 84, 95-101 (1978)

40. Newmark, A.K. \& J.R. KnOwles: Acyl- and amino-transfer routes in pepsin-catalyzed reactions. J. Am. Chem. Soc. 97, 3557-3559 (1975)

41. OKa, T. \& K. Morinara: Peptide bond synthesis by thermolysin. J. Biochem. 88, 807-814 (1980)

42. Oyama, K., K. Kihara \& Y. Nonaka: On the mechanism of the thermolysin-catalyzed condensation reaction of $\mathrm{N}$-benzyloxycarbonyl-L-aspartic acid withL-phenylalanine methyl ester. J. Chem. Soc. Perkin Trans. 2, 356-360 (1981)

43. Pel legrini A. \& P.L. Luisi: Pepsin-catalyzed peptide synthesis. Biopolymers 17, 2573-2580 (1978) 44. SACHDEV, G.P. \& J.S. FRUTON: Kinetics of action 
of pepsin on fluorescent peptide substrates. Proc. Natl. Acad. Sci. USA 72, 3424-3427 (1975)

45. Sawyalow, W.W.: Zur Theorie der Einweissverdauung. Pfluger Arch. Ges. Physiol. 85, 171-225 (1901)

46. SEGEL, I.H.: Enzyme Kinetics. New York, pp. 274-283 (1975)

47. Silver, M.S. \& S.L.T. JAmES: Surprising consequences of the tendency of pepsin to catalyze condensation reactions between small peptides. Biochim. Biophys. Acta 743, 13-22 (1983)

48. TSENG, M.. S. WU \& K. WANG: Enzymic synthesis of oligopeptide. VI. The mechanistic features of pepsin-catalyzed peptide synthesis. Tetrahedron 39, 61-66 (1983)

49. Viola, R.E., F.M Rauschel, A.R. Rendina \&
W.W. Cleland: Substrate synergism and the kinetic mechanism of yeast hexokinase. Biochemistry 21, 1295-1302 (1982)

50. WAYNE, S.I. \& J.S. FRUTON: Thermolysin-catalyzed peptide bond synthesis. Proc. Natl. Acad. Sci. USA 80, 3241-3244 (1983)

51. Weaver, L.H., W.R. Kester \& B.W. Matthews: A crystallographic study of the complex of phosphoramidon with thermolysin. A model for the presumed catalytic transition state and for the binding of extended substrates. J. Mol. Biol. 114, 119-132 (1977)

52. Widmer. F. \& J.T. JohanSEn: Enzymatic peptide synthesis. Carboxypeptidase $Y$ catalyzed formation of peptide bonds. Carlsberg Res. Commun. 44, 37-46 (1979) 